\title{
Abc da greve: a câmera, o povo, a política ${ }^{1}$
}

\author{
Pedro Vaz Perez
}

1 A primeira versão deste texto foi apresentada no seminário A visibilidade dos anônimos, promovido pelo Grupo de Pesquisa Mídia e Narrativa, da Pontifícia Universidade Católica de Minas Gerais (PUC-MG), em Belo Horizonte, nos dias 06 e 07 de novembro de 2013.

2 Mestre pelo Programa de Pós-Graduação em Comunicação da Pontifícia Universidade Católica de Minas Gerais (PUCMG).pedrovazperez@gmail.com. 


\section{Resumo}

O estudo investiga o filme $A b c$ da greve, de Leon Hirszman, problematizando as relações entre o fenômeno popular e suas representações midiáticas. Um cineasta, com a câmera na rua, no devir do acontecimento histórico: o que ele filma? Como reconstrói o acontecimento no qual também está imerso? Para tal reflexão, serão abordadas as formas com que as relações dialéticas entre indivíduo, massa e líder são representadas no filme, bem como o emprego de um método materialista de investigação da realidade e do uso dialético da montagem. Também serão consideradas as possibilidades maquínicas do intervalo entre cinema e televisão como geradoras de linguagem: a técnica conforma e potencializa o método do documentarista rumo ao ensaio político e à síntese dialética da greve geral.

\section{Palavras-chave}

Cinema, política, estética, $A b c$ da greve, Leon Hirszman.

\section{Abstract}

This paper investigates the movie $A b c$ da greve, directed by Leon Hirszman, concerning the relationships between popular phenomena and its media representations. One moviemaker on the streets, with his camera, in the middle of a historical event process: what does he film? How does he reconstruct an event in which he is also immersed? Thus, this study discusses the ways the dialectical relationship among the individual, the mass, and one leader are represented in the movie. It also analyses, in regard of the documentary film, the uses of a materialist method of examining reality and yet the dialectical technique of film editing. This text also considers the machinic possibilities that sets apart cinema and television for its language elements: the technique enabled the documentarian to put his method in favor of a political argument and a dialectical synthesis of the industrial strike.

\section{Keywords}

Cinema, politics, aesthetic, Abc da greve, documentary movie, Leon Hirszman. 
A ida do povo às ruas para reivindicar, quaisquer que sejam os projetos, é fenômeno merecedor de atenção. A apropriação do espaço público por aqueles que literalmente formam o que é público, por si só, é fundamental para o desenvolvimento da democracia e da vida em sociedade. Como propõe Rancière (2005), uma "partilha do sensível" remete não só à divisão do todo em partes iguais, mas também à participação em um conjunto comum, (com)partilhado por todos. O povo na praça pública é acontecimento sensível que embaralha a organização vigente da política.

Nesse cenário, há um cineasta com uma câmera na praça em meio a uma manifestação: o que ele pode? O que ele filma? Como ele registra aqueles acontecimentos? Como seleciona, recorta e articula aquelas imagens e sons? Qual ou quais os sentidos ele imprime àquela sequência de imagens? Em suma, quais os mecanismos construídos para significar o real? Influenciado pelas manifestações populares recentes no Brasil e suas relações com as representações midiáticas, busquei dar um passo atrás e olhar, na história, exemplos que possam jogar luz sobre a imbricação mídia-manifestação nos dias atuais, observando a atuação prática e direta de jornalistas e documentaristas no presente. De forma que arriscamos trazer aqui subsídios que possam influenciar suas - ou nossas decisões, posições de câmera, tempos de corte e lugares de fala.

Elegemos, como objeto principal, o filme $A b c$ da greve, de Leon Hirszman, realizado em 1979 e lançado em 1990. Quando o diretor se preparava para filmar a ficção Eles não usam black-tie (1981), em São Bernardo do Campo, eclodiu a greve geral no ABC paulista, a maior da história do país. Com poucos recursos, reuniu uma enxuta equipe para acompanhar de perto todo o desenvolvimento grevista. Os 85 minutos de $A b c$ da greve reportam os diversos acontecimentos daqueles dois meses de movimentação: os 15 dias de greve geral, os 45 dias de trégua e negociação, e o desfecho final. Adquirir uma compreensão abrangente do fenômeno era fundamental para a produção de registros que fossem significativos, já que, segundo o diretor, havia escassez de filme virgem (HIRSZMAN, 2009). Em sessenta dias, foram filmadas apenas $25 \mathrm{~h}$ de negativos, 
mas com imagens bastante fortes e sintéticas. Em entrevista, o pesquisador Ismail Xavier afirma que $A b c$ da Greve mostra um cineasta "capaz, de um lado, de trabalhar a documentação do fato (...), essa assembleia que está acontecendo, aqui e agora; e ao mesmo tempo ser capaz de, nesse registro, pegar o ponto dramático daquela experiência" (XAVIER, 2013). Vemos um trabalho bastante apurado sobre a imagem e suas possibilidades de significação.

À época, ao comentar sobre o processo do documentário, Leon Hirszman afirmou: "Estamos fazendo, agora, um filme de intervenção. Seu caráter jornalístico é fundamental" (HIRSZMAN, 2009, p. 52). Cinema, jornalismo e intervenção são, portanto, palavras-chave neste estudo. Mas, o que ele parece querer dizer com isso? Pensamos que se trata da consciência de haver questões jornalísticas importantes no $A B C$, mas que, na visão do realizador, não tinham vazão pelos órgãos midiáticos comuns. Por exemplo, a questão do que é a greve, em seus diferentes fatores. Quem são esses grevistas? Quais são as forças políticas em tensão? O que está sendo reivindicado? Como lideranças sindicais e os demais operários se relacionam? Quais as causas, superficiais e profundas, da greve? Como a luta social se insere num contexto em que acena com a abertura democrática? E como se entrelaçam interesses econômicos multinacionais e um discurso político oficial de cunho nacionalista? Parece tratar-se, portanto, de um extenso trabalho de investigação jornalística dentro de um documentário engajado, a partir de um ponto de vista materialista e dialético. Claro, não sem algumas doses de ironia por parte de seu diretor.

As respostas a essas hipotéticas questões jornalísticas, que formulei a partir do que vimos no filme, no método de Leon Hirszman não podem ser simplórias. Como um bom materialista dialético, o diretor interpela os fenômenos do ponto de vista de seu movimento, de suas transformações, de seu desenvolvimento, de sua dinâmica, de suas contradições internas, de seu passado e seu futuro. Assim, $A b c$ da greve oferece um quadro das forças políticas em ação e apresenta uma investigação materialista sobre a condição de vida e de trabalho daqueles operários e seus familiares. Vasculha, com a câmera, as nuances da greve, tanto 
seu desenvolvimento no tempo presente, seus estopins, dia após dia, como suas causas mais profundas e crônicas. Trata, assim, das condições materiais de vida daqueles operários: alimentação, saúde, habitação, além dos modos e dos instrumentos de produção necessários para o desenvolvimento social e das condições de trabalho. Ou seja, "a situação real daqueles que lidam com produtos químicos, gases, que engolem tudo, mastigam aquele ferro, engolem aquele fel" (HIRSZMAN, 2009, p. 52).

O filme é estruturado a partir de uma noção dialética da montagem, que busca colocar em oposição, na sintaxe do filme, imagens com conteúdos que entram em conflito, um sobre o outro. Apresenta desde oposições mais básicas, como o bairro pobre sobreposto pelo bairro rico, até cenas com nuances, como os gritos que clamam "Lula, Lula!" na praça pública, seguidos pelo corte seco que revela o líder na Igreja. Anteriormente, ele já havia sido equiparado, nos dizeres de uma faixa, a Jesus Cristo. Importante ressaltar que a comparação feita não busca uma simples analogia, mas sim uma complexa imbricação existente entre teologia e política, entre fé e revolução, que subsiste na relação lídermassa. Tal é a compreensão filosófica, de acordo com Helena Salém (1997), cara a pensadores marxistas de origem judaica, como Walter Benjamin e o próprio Hirszman. Assim, parece-nos que o uso dialético da montagem, em $A b c$ da greve, funciona mais como uma investigação marxista, ou seja, enquanto método de trabalho, do que como uma explicação marxista, enquanto dogma.

Leon Hirszman participou do grupo de realizadores do Cinema Novo no Brasil e sempre buscou a integração entre cinema e cultura popular. Em sua filmografia estão latentes sua ascendência polaco-judaica e a formação marxista e brechtiana, que podem ser observadas tanto em curtas-metragens, como a ficção Pedreira de São Diogo (1962), que tematiza uma rebelião de trabalhadores valendo-se de recursos da montagem dialética eisensteniana, como no documentário Maioria absoluta (1964), no qual buscou dar voz aos analfabetos do país. Já em trabalhos posteriores ao evento do golpe militar, o diretor incorporou a seu estilo uma postura etnográfica, aberta ao improviso, 
identificável, por exemplo, nos curtas sobre Nelson Cavaquinho (1969), em Partido alto (1976), que documenta o desenvolvimento do samba de improviso, e na série Cantos de trabalho (1975; 1976), que registra formas de fazer de cacaueiros, cortadores de cana e o "mutirão do barro".

Abc da greve é um filme político, de intervenção. Toda a trajetória ideológica e de engajamento de Leon Hirszman está presente, e sua posição ao lado dos grevistas é nítida. Mas parece haver aqui, em relação a produções anteriores, uma variação, uma espécie de desvio no entendimento do político. Leon Hirszman não usa o filme como veículo para a enunciação de um discurso ufanista, mas sim para apresentar uma ação política concreta, afinal, como ele diz, "a política está se desdobrando na realidade" (HIRSZMAN, 2009, p. 53). Os trabalhadores são filmados a partir de sua própria experiência, que se desenvolve em frente à câmera e independentemente dela. De certa forma, o filme ecoa a constatação de Glauber Rocha de que "o povo é o mito da burguesia" (ROCHA, 2004, p. 250). Pois, há, no filme, uma compreensão complexa sobre o que é aquela massa de trabalhadores em greve. Ela não é formada por uma consciência social externa a ela, mas, ao contrário, pelo ser social.

Damos mais um passo atrás. "Filmes de massa", é esse o nome atribuído por Sergei Eisenstein aos primeiros filmes soviéticos, realizados quando "o cinema foi chamado a incorporar a filosofia e a ideologia do proletariado vitorioso" (EISENSTEIN, 2002, p. 25). Ele aponta, nesses filmes, a forte presença da noção de coletivo e do meio, um coletivo unido e impulsionado por uma vontade única: a do partido. É a mesma relação encontrada entre o povo, a cidade e a fábrica, em $A$ greve (1925); ou entre os marinheiros e o navio, em $O$ encouraçado Potemkin (1925). As aproximações foram construídas pela estrutura geral da composição do plano. São grandes filmes, mas recebem uma autocrítica por parte do diretor. Eles teriam pecado por uma "compreensão da massa como herói", que acabou por produzir uma "representação unilateral da massa e do coletivo; unilateral porque coletivismo significa o desenvolvimento máximo do indivíduo dentro do coletivo" (EISENSTEIN, 2002, p. 24). Tratou-se, no entanto, 
de um desvio necessário, segundo o diretor, para o fortalecimento do socialismo e do próprio cinema soviético. Para Benjamin:

\footnotetext{
O proletariado consciente de sua classe forma uma massa compacta somente a partir de fora, na mente de seu repressor. No instante em que o proletariado assume a luta de libertação, a sua massa aparentemente compacta, na verdade, já se dispersou. Ela cessa de estar sob o domínio de meras reações; ela passa à ação. A dispersão das massas proletárias é produto da solidariedade (...) a oposição morta e não-dialética entre indivíduo e massa é abolida (BENJAMIN, 2012, p. 301-302).
}

De acordo com o autor, ciente de que quanto mais compactas são as massas, mais determináveis suas reações, o fascismo convergiu para uma estetização da vida política, construindo uma "constituição corrupta da massa" no lugar da consciência de classe do proletariado. (BENJAMIN, 2012, p. 301). Isto pode ser observado, por exemplo, nos blocos coesos do incômodo O triunfo da vontade (1935), documentário dirigido por Leni Riefenstahl, que registra o congresso do partido nacional-socialista alemão.

Já em $A b c$ da greve, não raro as imagens sobram após assembleias: a câmera permanece e se insere no devir da multidão, que é heterogênea, caótica. Nesse instante, o tempo se dilata e provoca uma ruptura na paixão inflamada que tomava conta do evento anterior. A montagem, portanto, produz certo afastamento crítico em relação ao próprio tema colocado em discussão: o engajamento na assembleia, por exemplo. Ao mesmo tempo, demonstra outras facetas daquela massa, podendo alternar entre os planos gerais do coletivo e os primeiros planos mostrando operários que a constituíam. Tal exercício de montagem não se torna mera ilustração da massa a partir de rostos, pois o que vemos são sujeitos em ação, assumindo posições políticas concretas.

Mesmo tendo em vista toda a formação política e ideológica de seu realizador, membro do Partido Comunista Brasileiro desde seus 14 anos de idade, não vemos, de maneira geral, em $A b c$ da greve, a postura de um pensador com "ideias puras e sublimes" oferecidas a uma massa que julga alienada. É o próprio Leon Hirszman quem reconhece: "Não é o intelectual que quer, é a massa que exige, no seu 
processo de organização. (...) Eu, como intelectual, não quero mais ver como eles estão alienados. Alienado estou eu dessa realidade viva e quente" (HIRSZMAN, 2009, p. 57). Seu projeto era o de organizar um material que servisse, com justiça e justeza, à memória do operariado, que fosse útil em seu desenvolvimento e não um filme que insuflasse a massa a partir de uma posição externa.

Aqui, a tecnologia do cinema é usada a serviço da causa. Nas últimas décadas, a sofisticação dos equipamentos de filmagem e captação de som, mais leves e baratos, possibilitou, gradualmente, que a sociedade passasse a registrar suas próprias manifestações, fato que vem modificando os próprios acontecimentos. Regina Mota (2001) propõe que esse desenvolvimento tecnológico, do qual o cinema se serve, é produto de uma interação crítica entre cinema e televisão, meios que andam aos pares, influenciando-se mutuamente. Para a autora, no intervalo entre as duas mídias há um processo gerador de linguagem que faz emergir uma "arte híbrida", não é nem cinema tradicional, nem televisão convencional.

Com a maquinaria desenvolvida para o registro das "atualidades", surgiu nova margem de inventividade ao cineasta, que passou a narrar com a própria imagem, em tempo real, recriando o evento durante o seu próprio desenrolar, encenando e participando ao mesmo tempo, de forma ativa, e não somente observadora. A técnica força o método. Parece ser nesse sentido a declaração de Leon Hirszman de que $A b c$ da greve é um filme-processo, aberto à surpreendente "riqueza da transformação do real" (HIRSZMAN, 2009, p. 55). O filme reconstitui o acontecimento instalando-se nele como dentro de um devir. Mas, parece-nos que, assim como no jazz, ou no samba de Partido Alto, trata-se de um improviso a partir de bases sólidas.

Televisão e cinema se imbricam, mas também se diferem, numa relação dialética. Em entrevista, Hirszman fala sobre querer "filmar todo dia para registrar e acompanhar os fatos". E responde quando Adrian Cooper, colaborador da produção e co-montador do filme, fazendo as vezes de entrevistador, o interpela com "mas isso de certa forma a Globo faz...": "Faz, mas esvazia. O 
cinema organiza o material, que permanece cristalizado (...). [A televisão] passa uma impressão imediata sujeita a um desgaste muito forte. (...) não tem a permanência do filme" (HIRSZMAN, 2009, p. 53).

É preciso, portanto, marcar uma diferença essencial entre a técnica, o modo de fazer caro à televisão, e sua inserção em um universo empresarial, capitalista, que controla os meios de produção e exibição. Evidentemente, um documentário não é uma reportagem de televisão, mas seus métodos surgem do mesmo intervalo crítico, em benefício mútuo. Dessa forma, as construções de sentido do cinema engajado, como é o caso de $A b c$ da greve, também podem ser mais uma vez apropriadas pelo telejornalismo.

A obra de arte, de acordo com Benjamin, passou por uma transformação que Ihe retirou a aura, ao mesmo tempo em que a lançou no terreno da política. No cinema, aponta o autor, "obra de arte" não é o material reproduzido (película), nem o próprio momento da reprodução. A arte está no que é posto em cena ao alcance da câmera de uma dada maneira, ao gosto do realizador, e na posterior articulação entre os segmentos mencionados. Logo, são as possibilidades técnicas e maquínicas do cinema que entram em relações diretas com o político. Isso ocorre na "genial condução da objetiva" (BENJAMIN, 2012, p. 306), quando "a câmera intervém com seus recursos auxiliares, suas imersões e emersões, interrupções e isolamentos, ao distender e comprimir o decurso temporal, ao ampliar e reduzir" (BENJAMIN, 2012, p. 307).

Nesse sentido, podemos interpelar as cenas de operários em atividade no interior da fábrica e, sobretudo, a sequência final de primeiros-planos mostrando trabalhadores suados e desgastados. Após a greve, eles estão de volta ao seu inóspito ambiente de trabalho: a luta continua. Mas, talvez, esses planos ofereçam ao espectador toda a potência - enquanto virtualidade, vir a ser - daqueles trabalhadores, das individualidades que dão forma ao coletivo. O outro nos olha de frente. Essa imagem persiste, permanece. E aqui, mais do que nunca, como propõe Benjamin, o cinema se apresenta como a revanche do homem perante a máquina. Esses trechos parecem sintetizar homens com uma 
máquina - a do cinema - em punho filmando outros homens operando outras máquinas. Passa-se uma operação política, o homem colocando a aparelhagem a serviço de seu próprio triunfo. Neste filme único, a afirmativa de Benjamin de que "o cinema $(. .$.$) pode ser um instrumento extraordinário de representação$ materialista" (BENJAMIN, 2012, p. 298) parece atingir um novo patamar.

\section{Considerações finais}

Este trabalho apresenta uma aproximação incipiente em relação ao filme de Leon Hirszman estando, por isso, sujeito a problemas e lacunas. Muitas das questões que o filme suscita ficaram de fora. O artigo marca, no entanto, o início de uma pesquisa de maior fôlego, que poderá abranger corpus mais amplo, investigando filmes que tenham registrado os fenômenos históricos no momento mesmo em que aconteciam, instalando-se no devir do acontecimento.

$A b c$ da greve é um filme que parte das possibilidades maquínicas do audiovisual para fazer um ensaio político e uma síntese dialética da greve geral, a partir de uma abordagem materialista. O filme traz uma narração off, de Ferreira Gullar, mas a palavra falada do narrador oficial, em geral, não é dominante. Ela não tem a carga analítica vista, por exemplo, em Maioria absoluta (1964). Em $A b c$ da greve, as tensões, os antagonismos políticos, a relação do líder com a massa e sua própria composição dialética são construídas, em sua maioria, a partir da imagem e do registro direto de som. A imagem vence.

Para Jean Claude Bernardet (2003), as entrevistas realizadas in loco, sem o controle minucioso do estúdio e da preparação do texto, funcionam como "locutores auxiliares". Nesse filme, no entanto, esses auxiliares crescem, tornam-se principais, compõem eles mesmos a matéria fílmica. Suas vozes são ouvidas, seus rostos são vistos, sem que o viés engajado e militante do filme, que existe, acabe por elidir as complexidades do movimento grevista em nome de um discurso ufanista.

$A b c$ da greve traz a marca de seu realizador. Não há um abandono da estética para se produzir um material político, muito pelo contrário. No entanto, se existe uma politização da estética, ela se dá com grande dose de ética. Respeitar 
os operários, sujeitos do filme, não significa, nessa produção, torná-los heróis, de forma idealizada. Mas, sim, construir uma memória audiovisual que possa servir, diretamente, à reflexão por parte daquele movimento. E, indiretamente, para o pensamento sobre democracia e antagonismos de classe no Brasil, na América Latina, no mundo. É uma obra atemporal. Sobrevive. É, também, uma fonte rica para discussões acerca das relações entre estética e política no cinema brasileiro, que há mais de cinco décadas têm sido tão polêmicas quanto frutíferas. Tais tensões estão longe de serem resolvidas, afinal, como constata Glauber Rocha, a mudança das "condições políticas e mentais exige um desenvolvimento contínuo dos conceitos de arte revolucionária" (ROCHA, 2004, p. 249).

Se, para Benjamin, arte no cinema é a maneira como o assunto é colocado em cena, frente à câmera, em $A b c$ da greve é a própria vida dos operários grevistas que constitui a obra de arte, levando-a ao terreno do político. Mas aqui retornamos ao mesmo movimento em falso, com o qual estetas políticos não cessam de se deparar. A vida como obra de arte é o ideal fascista. De forma que parece haver, a cada plano, a cada corte, uma correção ética, uma ação desmistificadora dos nacionalismos culturais, contra alguns mitos e tradições conservadoras e reacionárias.

Seja para Leon Hirszman ou para Glauber Rocha, como em Benjamin e Eisenstein, a máquina do cinema assumiu posição de destaque na arte política: poderoso instrumento de comunicação capaz de agitações psicossociais e políticas de consequências imprevisíveis. No entanto, o cinema propôs um desvio a partir da televisão. $A b c$ da greve se inscreve nesse intervalo entre cinema e televisão, nessa arte híbrida. Mas Maioria absoluta já bebia dessa relação.

É válido relembrar que grandes diretores atuaram de maneiras variadas na telinha, como Jean Renoir, Roberto Rossellini, Jean-Luc Godard, Alfred Hitchcock, Krzysztof Kieślowski, David Lynch, além de Glauber Rocha e do próprio Leon Hirszman, que realizou Que país é esse para o canal italiano RAI. Em 1946, Serguei Eisenstein, para quem o plano cinematográfico era mais resistente que um granito, já previa as relações frutíferas entre a montagem cinematográfica 
e o fluxo da televisão. "De repente, a televisão puxa todo o processo para frente, para o momento da percepção. Assiste-se assim à fusão incrível de dois extremos" (EISENSTEIN, 2002, p. 11-12). Como disse Glauber Rocha, o futuro do cinema é o filmevídeo, o kinotev. Mas a aproximação entre cinema e televisão, constantemente vista como pouco nobre, merece receber, ainda, de nossa parte, uma investigação mais nuançada, que até aqui não pudemos realizar. 


\section{Referências}

BENJAMIN, W. "A obra de arte na era de sua reprodutibilidade técnica". In: DUARTE, R. (org.). O Belo autônomo: textos clássicos de estética. 2a ed. Belo Horizonte: Autêntica; Crisálida, 2012, p. 277-314.

BERNARDET, J. C. Cineastas e imagens do povo. São Paulo: Companhia das Letras, 2003.

EISENSTEIN, S. A forma do filme. Rio de Janeiro: Jorge Zahar, 2002.

HIRSZMAN, L. "Entrevista". In: Abc da greve: livreto. São Paulo: Videofilmes, 2009, p. 52-63.

MOTA, R. A épica eletrônica de Glauber: um estudo sobre cinema e TV. Belo Horizonte: Editora da UFMG, 2001.

RANCIÈRE, J. A partilha do sensível: estética e política. São Paulo: Exo Experimental; Editora 34, 2005.

ROCHA, G. Revolução do Cinema Novo. São Paulo: Cosac Naify, 2004.

SALEM, H. Leon Hirszman: o navegador das estrelas. Rio de Janeiro: Rocco, 1997.

XAVIER, I. Programa Diverso: Leon Hirszman. 31 out. 2013. Disponível em: http://www.youtube.com/watch?v=Xf9y77pCHMU. Acessado em: 02 nov. 2013.

\section{Referências audiovisuais}

A greve. Sergei Eisenstein. União Soviética, 1925, 82 min., mudo, pb. 
O encouraçado Potemkin. Sergei Eisenstein. União Soviética, 1925, 75 min., mudo, pb.

O triunfo da vontade. Leni Riefenstahl. Alemanha, 1935, 114 min., son., pb.

Pedreira de São Diogo. Leon Hirszman. Brasil, 1962, 18 min., son., pb.

Maioria absoluta. Leon Hirszman. Brasil, 1964, 20 min., son., pb.

Nelson cavaquinho. Leon Hirszman. Brasil, 1969, 17 min., son., pb.

Partido alto. Leon Hirszman. Brasil, 1976, 23 min., son., cor.

Cantos de trabalho: mutirão. Leon Hirszman. Brasil, 1975, 13 min., son., cor.

Cantos de trabalho: cana-de-açúcar. Leon Hirszman. Brasil, 1976, 8 min., son., cor.

Cantos de trabalho: cacau. Leon Hirszman. Brasil, 1976, 10 min., son., cor.

Abc da greve. Leon Hirszman. Brasil, 1979, 85 min., son., cor.

Eles não usam black-tie. Leon Hirszman. Brasil, 1981, 120 min., son., cor. 